\title{
Reflection on the pre-practicum nursing students' integrated competence training under the guidance of caring experience
}

\author{
Huiling Li, Lu Liu, Lu Lin*, and Hongyan Meng* \\ School of Nursing Soochow University, 215006, Suzhou, China
}

\begin{abstract}
Purpose: Pre-practicum competence training for nursing students' could help them adapt to the clinical work better. However, the efficacy of the training under the guidance of caring experience is not known. Our study aims to discuss the model and significance of caring experience-oriented integrated competence training for nursing students, and to provide practice guidance for exploring new teaching models.
\end{abstract}

Methods: "Warm-up training" course of integrated competence training was carried out among nursing students before clinical practicum. The effects of training were measured by comprehensive assessment and self-experience reports before and after the practicum.

Results: Two themes were extracted by analyzing 250 self-experience reports, which were "caring experience in the teaching" and "caring experience in clinical practice". Students before practicum responded that the course greatly promoted their personal growth and quality, and a more humanistic approach was integrated into nursing profession. Students after practicum showed good self-perception, stronger comprehensive ability and better communication skills.

Conclusions: The training could help students to develop the quality of caring, the skills of communication and creative thinking, and maintain caring emotions and sensitivity to patients; it can also help students to stand out among peers during collaboration with stronger comprehensive quality, which lays a solid foundation for cultivating outstanding nursing talents of next generation.

\section{Introduction}

Humanistic care refers to the active will, awareness and responsibility to care for others in concrete action, and the intrinsic quality integrated by nurses' emotions and the competence to serve patients [1]. The integration of humanistic care into education of nursing has gradually become the priority of nursing education development, which focuses on nurses' sublimation of personal emotional experience [2]. At the same time, to help nursing students successfully adapt to their clinical role and reform of nursing education system, many schools conducted comprehensive competence training before nurses' internship and certain progress has been achieved [3].

The training mode integrating humanistic care and comprehensive competence has increasingly caught attention, as caring experience oriented comprehensive competence for nursing students before internship helps to mould students' caring, reduce tensions between doctors and patients, foster patient-oriented professional ethics and work philosophy as well as improvement of job satisfaction [4]. This paper conducted a summary and exploration in regard to the training model of the nursing students' comprehensive competence and their relevant experience before internship at X University.

\section{Subjects}

Undergraduates at school of nursing underwent an annually held four-week comprehensive competence training before internship, the participants of which totaled 250 since 2011, among whom there were 53 boys and 197 girls aged from 21 to 27 , with an average age of ( 24.56

\section{$\pm 1.78) .53$ nursing students were included this year.}

Each student should fully participate in the training while clinical nurses from school of nursing and affiliated hospitals constituted the teaching force, giving students professional guidance. The teaching staff was from the core faculty bank of school of nursing at X University and had rich teaching and clinical practice.

\section{Methods}

\section{Design of the training mode}

The training model for comprehensive competence constructed under the guidance of Watson's Theory of Human Caring comprises five modules [5]: experiencing caring, perception of patients' needs, simulated situations, team learning and interprofessional cooperation. Experiencing caring refers to lectures on humanistic caring and videos on communication; perception of patients' needs means role-play of patients and nurses [6]; simulated situation refers to simulated scenarios featuring humanistic caring; team learning refers to peer

Correspondence to: Lu Lin, School of Nursing Soochow University, 215006, Suzhou, China, E-mail: aqing1748@126.com

Hongyan Meng, School of Nursing Soochow University, 215006, Suzhou, China, E-mail:1hl8543@126.com

Key words: caring, nursing, students, competence

Received: June 07, 2016; Accepted: June 27, 2016; Published: June 30, 2016 
support and resource sharing; and interprofessional cooperation refers to cooperation with medical students and field drill [7]. The field training of all these five modules was infused with humanistic caring, which were independent from yet interacted with each other. In accordance with the requirements of the learning task, students are divided into six groups, with the training of each module deployed according to respective group with one teacher (Table 1).

\section{The theoretical basis of the teaching}

The program under the guidance of Bruner's discovery teaching mode carries out each module's lecturing in accordance with the discovery theory of question, creation of problem situations, hypothesizing, evaluation, verification and conclusion [8]. The theory emphasizes students' self-discovery and self-perception, meaning that students should take the initiative to learn how to find out problems and solve them as well as development of their own initiative to learn and transferring ability.

\section{Results evaluation}

Students' training result after the completion of lecturing will be assessed by teachers trough assessment and evaluation on comprehensive competence; with self-assessment and peer assessment between team members, including perception, suggestions and comments on training pattern; teachers' remark on students' performance from perspectives of caring and perception awareness, professional skills, team cooperation ability;

Each student at the end of training and after the completion of three-month internship shall hand in an anonymous self-experience report, in which comprehensive competence will be evaluated by way of case display, the score totals 100 points, covering the following areas: professional and moral qualities (20\%), professional knowledge (30\%), practical skills (30\%) and communication skills (20\%).

\section{Outcome analysis}

Evaluation table employs to show nursing students' scores in various aspects while experience report researchers conduct coding analysis on 250 post-training experience reports and 197 postinternship experience reports and extract keywords, and during that process, researchers shall involve themselves with emotion and cognition and carefully analyze and read those reports while refining keywords until there is no new keywords.

\section{Results}

Evaluation results of nursing students' comprehensive competence (Table 2).

Extracted subjects by condensation: Nursing Students' Caring Experience in Lectures and Nursing Students' Caring Experience in
Clinical Practice.

\section{Subject 1: nursing students' caring experience in lectures before internship}

\section{Sensitivity inspired by caring experience}

Understanding of love is the cornerstone of quality caring, such kind of love is contained in lecture edification and presentation of video courses [9], including teachers' love for students, but there is also another kind of love saw and appreciated in lectures, which is an approach to disseminate the ability to love, fostering sensitivity to self and others. One nursing students wrote in his experience report: "When I finished the audio file and non-communication video played by my teacher, I was really impressed that there are so many wonderful moments in caring, that when a nurse holding a dying patient's hands greeted him softly in his ear and told him the pain relief that best suit him, at that moment, the patient must be fully entrusted himself to the nurse" "I once thought that our teacher gave us this lecture because he wanted to lecture us how to be gentle with patients, in fact, the true caring must be based on sound technical basis so as to give patients a sense of security, which is the most precious I have learnt". Such kind of experience can help nursing students learn how to communicate with patients, deepen mutual trust and encourage each other while naturally forge nurse-patient relation that is helpful and reliable.

\section{Experiencing authenticity in role-playing}

Nursing students perceive patients by way of patient-nurse roleplaying in training [10]. Allowance of existing phenomenal forces of Watson's Ten Caring Elements can help nursing students better understand patients and assist them in being confident in recovery through perception of patients' life experiences and subjective will. One nursing student wrote in the report: "I rarely went to hospital since I was a kid, and naturally I was treated as patient not so much, but in patient-nurse role-playing, I became a patient and by following the scenario I presented to my teacher a lot of challenges, including complaining about difficult recovery, discordant family relationship. And my teacher said that this is exactly the real field work, and we will encounter more complex and complicated problems. During the roleplaying, my teacher always patiently answered any question I asked and kept consoling me, at that moment I felt that patients could be to some extent happy actually! I did not trust my classmate when I was injected by him, and in fact that is exactly what patients feel in clinical practice, and it was at that moment when I understand what responsibility we shoulder". Role-playing helps nursing students to deal with problems from patients' perspective, thus resonate with patients and help with their recovery!

\section{Emotional interpretation by stimulated environment}

Another important segment of quality caring is first-hand

Table 1. Module contents under the guidance of Watson's humane caring theory.

\begin{tabular}{|c|c|c|c|}
\hline Name of module & Essentials of humane caring & Contents & Time allotment \\
\hline Experiencing caring & $\begin{array}{l}\text { Fostering of sensitivity toward self and others and development of } \\
\text { relationship that is helpful and reliable }\end{array}$ & $\begin{array}{l}\text { humane caring lecture and communication } \\
\text { video curriculum }\end{array}$ & the whole \\
\hline Perception of patients' needs & $\begin{array}{l}\text { Allowance of existing phenomenal forces, provision of supportive, } \\
\text { protective and improved social culture and psychological environment }\end{array}$ & role-playing of patient and nurse & 1 week \\
\hline Simulated situations & $\begin{array}{l}\text { Promotion and acceptance of positive and negative expression of } \\
\text { feelings, assistance to meet the patient's needs }\end{array}$ & $\begin{array}{l}\text { simulated scenarios full of humanistic } \\
\text { caring; }\end{array}$ & 2 weeks \\
\hline Team learning & $\begin{array}{l}\text { Formation of humane and altruistic value system } \\
\text { Enhancement of interpersonal interaction during teaching and learning }\end{array}$ & peer support and resource sharing; & the whole \\
\hline Interprofessional cooperation & $\begin{array}{l}\text { Systemic and scientific method to make decisions in solving problem } \\
\text { Insertion of confidence and hope in nursing practice }\end{array}$ & doctor-nurse cooperation and field drill. & 1 week \\
\hline
\end{tabular}


Table 2. Evaluation of nursing students' comprehensive competence.

\begin{tabular}{|c|c|c|c|}
\hline Serial number & Category & Mean & SEM \\
\hline $\mathbf{1}$ & Professional and ethnic quality (20\%) & 17.56 & 0.56 \\
\hline $\mathbf{2}$ & Professional knowledge (30\%) & 25.23 & 1.01 \\
\hline $\mathbf{3}$ & Practical skills (30\%) & 24.89 & 1.35 \\
\hline $\mathbf{4}$ & Communication skills (20\%) & 17.22 & 0.60 \\
\hline
\end{tabular}

experience which emphasizes involvement of nursing students in case display where real clinical case as the background and the teachers play the role of patient and nursing students learn to deal with different situations, including patient's positive and negative feelings, cultivate emotional communication ability and help meet the needs of different patients [11].

For example, when the patient went emotional, a nursing student thought to himself: "God, this patient has lost control of herself? I do not know how to comfort her, as all nurses on TV would tell her to be quiet. But I remember what our teacher told us that we should think in others' shoes, so I plucked up my courage and told her that I was her nurse and I was sorry to see she was unhappy and I could be her friend. Then gradually, the patient finally calmed down."

\section{Peer support and learning resources sharing}

Peer support refers to the auxiliary teaching method where each student is a learning companion for each other assisting classmates in participating in learning and practical activities to achieve overall development [12]. Nursing students in the study helped each other and shared experiences with others. One nursing student wrote in the report: "once I was very timid, when my teacher told me to give an injection for my patient role-played by my classmate, I simply could not do it, moreover, my classmate role-playing patient was very afraid of injection, obviously she saw my worry, but she courageously stretched her arm and took the injection. Encouraged by her, I took my first step, even it may be so insignificant in the eyes of others" "When taking my internship I was very worried about my performance, as there would be no one practicing with me. Later I learned that many students in my class have the same concern, so class leaders spontaneously formed a team with good ones assisting others every night, achieving overall proficiency." The use of peer support in caring helps form a humanealtruistic value system which will be gradually internalized. It is an unpaid voluntary initiative to help others, with good students setting up an example and simultaneous enhancement of emotional exchanges between students.

\section{Doctor-nurse cooperation and inspiration of clinical practice}

Improvement of clinical decision-making ability means sublimation of scientific and systematic nursing, and doctor-nurse cooperation in this training mode refers to field drill where a team formed by clinicians, nurses and nursing students stimulate a first aid emergency that presents real simulation and integrates doctors and nurses. "When I saw the doctors and nurses conducted CPR to a patient, I was impressed by the perfect cooperation between them and the accurate decision, I would be hurry-scurry if I participated in it" said a nurse having experienced the cooperation. "When I threw myself into an external chest compression for a stimulated patient, I cannot help thinking the real face of a patient who was so desperate and placed all his trust on me, I cannot let him down!" reported another nurse. This process allows nursing students to see the exemplary role of specialized clinical experts and help them fully understand the patient's vulnerability in special circumstances as well as help cultivate and inspire their creative critical thinking.

\section{Subject 2: experience perception of nursing students in clinical practice after internship}

\section{Caring implantation in clinical practice}

Three-month clinical practice allows nursing students to turn themselves into a clinician who would engrave in their heart love, patience, scrutiny, responsibility while be fully aware of the holy responsibility. Nursing students should be conscientious of patient's feelings when operating on patients, even if the operation is not successful, the patient will be encouraged and regain positive feedback.

\section{Inspiration deducted by discovery teaching}

Whether in the training before internship or clinical lecturing, all teachers followed the guidance of discovery lecturing theory and lectured nursing students to fully experience the process from asking questions to conclusion. "Every time we learnt rather a lot from the lecture and from my teacher who preferred no task questions, but asked us to think first and raise our own interpretation so as to make field deduction and finally judge and revise our conclusions" wrote one nurse. Actually I do not understand why my teacher asked us to operate directly just after one lecture of the replacement of drainage bag, later I learnt that that would allow us to encounter lots of problems which will compel us to reflect on the correct operation and master it". Field clinical practice is in fact more real and more complex, and nursing students can learn more which allow them to take care of patients with their own understanding of caring, learn how to assess patients by discovery lecturing, thus serve the patient's heart and soul.

\section{Caring cultivation by expertise priority}

As nursing is a major featuring teaching and learning, practical operation is not the only representation of the profession, but that integrating caring into expertise constitutes the sole way to cultivate professional ethnics. "If the nurse only gives simply an injection with no emotional communication or superficial communication, then he cannot be deemed as a professional. The teacher's role in setting an example during the lecturing is rather indispensable, "When I saw my teacher did catheterization for the patient while quietly explained to him, carefully protect his privacy, professionally operated on him, observed the patient's reaction and communicated with him, thus complete the operation with the fastest speed and the accurate precision, I was rather impressed! With teachers as an example inspiring nursing students with their expertise, nursing students were encouraged to work with heart and soul [13]. Meanwhile nursing students' communication skills were improved. As students said that practice is essential for effective exchanges with patients, namely, in-depth communication, all the factors are mutually complemented and reinforced by each other".

\section{Discussion}

\section{Cultivation and development of nursing students' humane caring under the caring guidance of the training model of comprehensive competence}

It can be concluded from Table 1 that nursing students have shown excellent professional ethics and communication skills, the results in the research are auxiliary subjective indicators used by teachers to evaluate students' comprehensive competence, which can reflect the emphasis of caring and emotional communication in students' case report even that it still can be improved from the scientific perspective. With or without proficient operations, all nursing students had learned to respect and care for patients, keep improving themselves and 
effectively communicate and exchange with patients and their families.

From the analysis of the experience reports, whether they are self-reflection, or first-hand experience, all nursing students reported with one accord that the training of caring-oriented comprehensive competence at X University had achieved certain accomplishment. Meanwhile, comprehensive learning in the form of groups has promoted the cultivation of nursing students' comprehensive competence, not only for the sake of improvement of comprehensive proficiency and competence [14], but more importantly, of the implantation of the thought of Watson's Ten Humanistic Caring Elements, which integrates caring elements into the training contents, shortens the gap between clinical practice and training and finally achieves seamlessdocking with clinical practice from the perspective of profession and caring.

\section{Self-perception of nursing students inspired by discover teaching can help improve their reflection and decision- making capacity}

According to Bruner, students should be discoverers under teachers' guidance and instruction, moreover, he emphasized that students should take their initiative to learn, with priority of self-exploration and self-perception. As showed by researches, discovery teaching can improve students' creative thinking ability and enhance students' initiative to acquire knowledge. The training of caring-oriented comprehensive competence under the guidance of the discovery teaching requires nursing students to cultivate their own sentiments from lectures, videos, clinical cases and practice, and reflect on their own caring ability in practical drill. Nursing students can integrate themselves into the training environment and convert and meditate on what they saw, moreover, students are able and interested in taking the initiative to learn, think and comprehend from the perspective from patients' perspective, reflect on their own deficiencies, and are willing to cooperate with others. Contents of the experience report verify the merits of discovery teaching, in which teachers' comprehension and implantation is inseparable. The lecturing of discovery teaching is of course not fixed, such as the import before class could be either 5-10 minutes of video interpretation or a debate related to the lecturing contents, which is also what need further in-depth reform in the future.

\section{Further improved and standardized training program that closely integrates expertise with humane caring}

As the results of the study indicated, the comprehensive competence training under the guidance of Watson's Ten Caring Elements and the Discovery Teaching allowed nursing students performed rather excellent quality caring in various aspects of lecturing and practice, therefore, the training needs to be popularized.

However, as evaluation table for comprehensive competence is just an auxiliary one, evaluation at X University is devoid of strict evaluation mechanism and theoretical framework, which is exactly what needs improvement in the future, for example, CBA, CES, and CDI can be employed as evaluation tools, caring ability before and after internship can be quantitatively measured, and with experience report, completed, multi-faceted and scientific feedback about the application of training contents can be reflected and employed as a scientific, efficient and mature teaching and training model [15].

At the same time, in answering to the call of quality caring required by modern medical science, $\mathrm{X}$ University will continue to focus on the integration of science and technology and quality caring, honor its commitment to the development of coordinated professionalism and caring competence, require nursing students to pursue quality caring and provide patients with humane caring [16]. In addition, humanistic quality of the faculty needs to be further enhanced, educational innovation with nursing capacity as the streamline should be actively conducted while internalizing students' imported professional emotion, moreover, a full range of nursing students comprehensive competence should be focused on, including occupational emotion, professional competence, caring ability, communication capacity and collaboration skills, furthermore, practical activities should be actively deployed to help improve nursing students' various capabilities with integration of profession and humane caring.

\section{Conclusions}

The training based on Watson's humane caring theory and Bruner's discovery teaching mode could help students to develop the quality of caring, the skills of communication and creative thinking. The training can help them to maintain caring emotion and sensitivity to patients; it can also help students to stand out among peers during collaboration with demonstrating stronger comprehensive quality, which accumulates strength for cultivating outstanding nursing talents of next generation. However, the evaluation on comprehensive competence is just an accessorial instrument. We know it is lack of rigorous evaluation mechanism and theory frame. This also prompts the teaching of our school to improve and standardize the examination in the future.

\section{Acknowledgments}

We thank the X University Teaching Reformation Foundation for providing funding for the study (NO. 2013(83)). The foundation played no role in data analysis or publication. We thank the teachers of our school and hospitals, and also thank the students provide their reports. We would like to thank $\mathrm{X}$ and $\mathrm{X}$ for their guidance and expertise on this study.

\section{References}

1. McCance TV, McKeana HP, Boore JR (1999) Craing: theoretical perspectives of relevance to nursing. $J$ Adv Nurs 30: 1388-1395. [Crossref]

2. Cook PR, Cullen JA (2003) Caring: as an imperative for nursing education. Nurs Educ Perspect 24: 192-197. [Crossref]

3. Tseng CN, Hsieh CJ, Chen KH, Lou MF (2013) Comparative study of an externship program versus a corporate-academic cooperation program for enhancing nursing competence of graduating students. BMC Med Educ 13: 108. [Crossref]

4. Pourghaznein T, Sabeghi H, Shariatinejad K (2015) Effects of e-learning, lectures, and role playing on nursing students' knowledge acquisition, retention and satisfaction. Med J Islam Repub Iran 29: 162. [Crossref]

5. Watson J (1991) Nursing: The Philosophy and science of caring. Boston: Little Brown and Company, 1979: Foreword by Madeleine Leininger.

6. Toghian Chaharsoughi N, Ahrari S, Alikhah S (2014) Comparison the Effect of Teaching of SBAR Technique with Role Play and Lecturing on Communication Skill of Nurses. J Caring Sci 3: 141-147. [Crossref]

7. Mickan S, Hoffman S J, Nasmith L (2010) World Health Organizations Study Group on Interprofessional Education and Collaborative Practice. Collaborative practice in a global health context: common themes from developed and developing countries. $J$ Interprof Care 24: 492-502.

8. Chin-Hsiang C (2012) Apply Discovery Teaching Model to Instruct Engineering Drawing Course: Sketch a Regular Pentagon. Procedia Soc Behav Sci 64: 457-466.

9. Foster K, McCloughen A, Delgado C, Kefalas C, Harkness E (2015) Emotional intelligence education in pre-registration nursing programmes: An integrative review. Nurs Educ Today 35: 510-517. [Crossref]

10. Wang W, Liang Z, Blazeck A, Greene B (2015) Improving Chinese nursing students 
communication skills by utilizing video-stimulated recall and role-play case scenarios to introduce them to the SBAR technique. Nurs Educ Today 35: 881-887. [Crossref]

11. Kesten KS (2011) Role-play using SBAR technique to improve observed communication skills in senior nursing students. J Nurs Educ 50: 79-87. [Crossref]

12. Kornhaber R, Wilson A, Abu-Qamar M, McLean L, Vandervord J (2015) Inpatient peer support for adult burn survivors-a valuable resource: a phenomenological analysis of the Australian experience. Burns 41: 110-117. [Crossref]

13. Saarikoski M, Kaila P, Lambrinou E, Pérez Cañaveras RM, Tichelaar E, et al. (2013) Students' experiences of cooperation with nurse teacher during their clinical placements: An empirical study in a Western European context. Nurse Educ Pract 13: 78-82. [Crossref]

14. Joan G (1995) How Students Learn Statistics. International Statistical Institute (ISI) 63: $25-34$.

15. Watson R, Deary IJ, Hoogbruin AL (2001) A 35-item version of the caring dimensions inventory (CDI-35): multivariate analysis and application to a longitudinal study involving student nurses. Int J Nurs Stud 38: 511-521. [Crossref]

16. Li HL (2005) The basic theory and application of humanistic nursing care. Chin $J$ Nursing 40: 878-880.

Copyright: (C2016 Li H. This is an open-access article distributed under the terms of the Creative Commons Attribution License, which permits unrestricted use, distribution, and reproduction in any medium, provided the original author and source are credited. 